\title{
Creating Friction: Infrastructuring Civic Engagement in Everyday Life
}

\author{
Matthias Korn \& Amy Voida \\ School of Informatics and Computing \\ Indiana University, IUPUI \\ \{korn,amyvoida\}@iupui.edu
}

\begin{abstract}
This paper introduces the theoretical lens of the everyday to intersect and extend the emerging bodies of research on contestational design and infrastructures of civic engagement. Our analysis of social theories of everyday life suggests a design space that distinguishes 'privileged moments' of civic engagement from a more holistic understanding of the everyday as 'product-residue.' We analyze various efforts that researchers have undertaken to design infrastructures of civic engagement along two axes: the everyday-ness of the engagement fostered (from 'privileged moments' to 'product-residue') and the underlying paradigm of political participation (from consensus to contestation). Our analysis reveals the dearth and promise of infrastructures that create frictionprovoking contestation through use that is embedded in the everyday life of citizens. Ultimately, this paper is a call to action for designers to create friction.
\end{abstract}

\section{Author Keywords}

Civic engagement; everyday life; infrastructuring; friction.

\section{ACM Classification Keywords}

K.4.2. Computers and Society: Social Issues; K.4.3. Computers and Society: Organizational Impacts.

\section{INTRODUCTION}

The object of our study is everyday life, with the idea, or rather the project (the programme), of transforming it. [..] We have also had to ask ourselves whether the everyday [..] has not been absorbed by technology, historicity or the modalities of history, or finally, by politics and the vicissitudes of political life. ([49]: 296, vol. 2)

The distinction between everyday life and political life is a highly problematic one for social theorists such as Lefebvre. And it is a distinction that is increasingly being challenged by researchers designing to support or provoke civic engagement in everyday life.

Copyright $\subset 2015$ is held by the author(s). Publication rights licensed to Aarhus University and ACM

5th Decennial Aarhus Conference on Critical Alternatives

August 17-21, 2015, Aarhus Denmark

DOI: http://dx.doi.org/10.7146/aahcc.v1i1.21198
Civic engagement encompasses the myriad forms of both individual and collective action that are geared toward identifying and addressing issues of public concern. Human-Computer Interaction (HCI) researchers employ diverse methods and design strategies to study, support, and provoke civic engagement. Some researchers work within mainstream politics to improve the efficiency with which citizens can engage with the state through e-government services $[6,73]$; to improve access to voting $[22,69]$; to seek input and feedback from citizens on public planning issues [24, 42]; or to foster dialogue, debate, and deliberation among citizens and with the state [5, 41, 65]. Researchers also work to foster civic engagement outside of the political mainstream, supporting the work of activists, protestors, and grassroots movements [2, 18, 35, 37, 51]. The sites in which political life takes place are not only sites of government, but also cities, neighborhoods, and communities.

Individual technologies and systems, and the civic engagement they support, are enabled by and based upon a myriad of different, 'layered', interwoven, and complex socio-technical infrastructures $[37,47,52,68]$. Yet, infrastructures of civic engagement are a particularly challenging site for $\mathrm{HCI}$ as there are competing forces at play. On one hand, infrastructures of civic engagement are fundamentally about engaging people; and even more so, they may be designed to engage people to enact change. On the other hand, infrastructures are typically invisible; they remain in the background and are taken for granted by their various users [68]. Even further, Mainwaring et al. warn that infrastructures, which are so conveniently at-hand, can breed complacency and stasis [52]. Infrastructures of civic engagement, then, must counter not only the challenges of provoking civic engagement through everyday life; they must also overcome challenges of complacency and stasis. These are the dual challenges that we take up in this research.

We advocate for the construct of friction as a design strategy to address the dual challenges of civic engagement. Following Tsing [70] and Hassenzahl et al. [30], we maintain that friction produces movement, action, and effect. Friction is not exclusively a source of conflict between arrangements of power; it also keeps those arrangements in motion [70]. In the infrastructuring of civic engagement, we believe that frictional design can help to expose diverging values embedded in infrastructure or 
values that have been left aside during its design. We also contend that frictional design can help to provoke people not only to take up more active roles in their communities but to question conventional norms and values about what it means to be a citizen, as well

In the remainder of the paper, we introduce the theoretical lens of the everyday to extend the emerging bodies of research on contestational design and infrastructures of civic engagement. Our analysis of social theories of everyday life suggests a design space that distinguishes 'privileged moments' from the more holistic 'productresidue' of everyday life. We analyze various efforts that researchers have undertaken to design infrastructures of civic engagement along two axes: the everyday-ness of the engagement fostered and the underlying paradigm of political participation. Our analysis reveals the dearth and promise of infrastructures that create friction-provoking contestation and debate through use that is embedded in the everyday life of citizens. Ultimately, this paper is a call to action for designers to create friction.

\section{THEORETICAL FOUNDATIONS}

Our research synthesizes strands of scholarship about everyday life, infrastructuring, and contestational design. We describe each strand of scholarship below, with a focus on their relationships to civic engagement.

\section{Everyday Life and Civic Engagement}

As technology has been woven into "the fabric of everyday life" ([77]: 94), it surrounds us in ever smaller and more invisible ways $[20,25]$ and reaches into multiple spheres of our lives [10]. But what is everyday life? Two social theorists-Lefebvre and de Certeau-have been most central in emphasizing everyday life as a legitimate site of study - a site that follows an underlying logic that is both relevant and discoverable.

According to Lefebvre-operating in post-war democratic France - the everyday is the space in which all life occurs ([49]: 686ff., vol. 3). ${ }^{1}$ It is not merely the stream of activities in which people engage over the course of their days (thinking, dwelling, dressing, cooking, etc.). Rather, everyday life more holistically understood is also the space between which all those highly specialized and fragmented activities take place. It is the residue. And further, everyday life must also be understood as the product of these activities, the conjunction and rhythms of activities that render meaning across fragmented activities.

For Lefebvre, everyday life is dialectically defined by contradictions between the body's personal rhythms and the rhythms of society or at the "intersection between the sector man [sic] controls and the sector he does not control" ([49]: 43, vol. 1). Everyday life includes the political; however,

${ }^{1}$ The three volumes of Lefebvre's Critique of Everyday Life [49] were published in 1947, 1962, and 1981, respectively.
Lefebvre contends that contact with the state has become a superficial and apolitical one in modern society:

Not only does the citizen become a mere inhabitant, but the inhabitant is reduced to a user, restricted to demanding the efficient operation of public services. [..] Individuals no longer perceive themselves politically; their relation with the state becomes looser; they feel social only passively when they take a bus or tube, when they switch on their TV, and so onand this degrades the social. The rights of the citizen are diluted in political programmes and opinion polls, whereas the demands of users have an immediate, concrete, practical appearance, being directly a matter for organization and its techniques. In the everyday, relations with the state and the political are thus obscured, when in fact they are objectively intensified, since politicians use daily life as a base and a tool. The debasement of civic life occurs in the everyday [..]. ([49]: 753-754, vol. 3)

For Lefebvre, one of the most fundamental concerns about civic engagement in modern society is that it has been confined to "privileged moments" ([49]: 114, vol. 1) special occasions or punctuated feedback cycles on public servants and service provision. Civic engagement has been degraded in the product and residue of everyday life. Lefebvre argues that "use must be connected up with citizenship" ([49]: 754, vol. 3) -that the everyday demonstration of concern for public services are as essential a facet of being a citizen as, e.g., voting or debate.

The significant tensions in everyday life that Lefebvre characterizes as playing out between personal and social rhythms are reprised somewhat, albeit with different framing, in the work of de Certeau. De Certeau [13] theorizes about the everyday as interplay between the social forces of institutional rituals and routines, "strategies," and the "tactics" opportunistically employed by ordinary people, who subvert these strategies as they go about their everyday lives. The performative and embodied nature of everyday life is also an emphasis taken up by more recent work in cultural studies [25].

Where strategies accumulate over time through the exertion of power (e.g., standardization), tactics live in and capitalize on what is in the moment ([13]: 37). The institutional rituals, routines, and their underlying representations, which influence and are influenced by the performance of the everyday, also, then, begin to form infrastructures for everyday life. Even amidst the push-andpull interdependence of the personal and the political, the tactics and the strategies, people still manage to carve boundaries amidst and around the everyday. And these boundaries, which are "normally taken for granted and, as such, usually manage to escape our attention" ([80]: 2), are important factors for consideration in the infrastructuring work that needs to be done if civic engagement is to be released from its confinement to privileged moments. 


\section{Infrastructuring Civic Engagement}

Infrastructures are the predominantly invisible and takenfor-granted substrates, both technical and social, that enable and support local practices [48, 68]. Infrastructures of civic engagement are those socio-technical substrates that support civic activities.

Infrastructures are relational. They are embedded in social structures, learned as part of membership in social structures, and shaped by the conventions of social structures [68]. The relationship between infrastructures and practices of use is dialectic, characterized by a dynamic interplay between standardization and the local practices they support at each site of use [68]. Infrastructure must, therefore, be understood as processual, evolving over time. What is infrastructure in one moment may become a more direct object of attention and work in the next, particularly when breakdowns occur-either when the technology ceases to work or when local practices change and deviate from standards implemented in infrastructure [58, 68].

Because infrastructures reflect the standardization of practices, the social work they do is also political: "a number of significant political, ethical and social choices have without doubt been folded into its development" ([67]: 233). The further one is removed from the institutions of standardization, the more drastically one experiences the values embedded into infrastructure-a concept Bowker and Star term 'torque' [9]. More powerful actors are not as likely to experience torque as their values more often align with those embodied in the infrastructure. Infrastructures of civic engagement that are designed and maintained by those in power, then, tend to reflect the values and biases held by those in power.

Infrastructures are also relational in a second sense. As they increasingly extend into everyday spaces, infrastructures are shaped by the spaces of everyday life and shape our encounters with those spaces; they are increasingly experienced spatially [19]. Infrastructures of civic engagement, then, must also contend with these spatiorelational experiences insofar as they engage with everyday space and the physical environment (e.g., [40]).

The processual and evolving character of infrastructure has led participatory design researchers to examine the tentative, flexible, and open activities of 'infrastructuring' with the goal of empowering sustainable change [47, 58, 67]. Researchers exploring civic engagement have increasingly focused on similar issues of empowerment and sustainability, moving beyond individual applications to engage more systematically with the infrastructures that support civic engagement (e.g., [47, 74]). This research has emphasized challenges associated with the fragmentation and interoperability of infrastructures currently supporting civic engagement [74]. However, the research community's critical engagement with infrastructure has also found that the full-service, ready-to-hand nature of many infrastructures may also invite complacency or disempowerment [52], which is particularly problematic for the infrastructuring of civic engagement.

\section{Contestational Design and Civic Engagement}

\section{Critical Design Roots}

There is a strong interest within the field of HCI to critique and provoke, to question and reflect in and through design - either on established social and cultural norms in general $[3,30,66]$, or within socio-political domains more particularly [1, 17, 37]. Dunne and Raby [21] discern between two modes of design-affirmative design and critical design:

The former reinforces how things are now, it conforms to cultural, social, technical, and economic expectation. [..] The latter rejects how things are now as being the only possibility, it provides a critique of the prevailing situation through designs that embody alternative social, cultural, technical, or economic values. ([21]: 58)

Critical design aims to question the status quo, revealing hidden values and agendas by designing provocative artifacts that adopt alternative values not found in mainstream design. Critical design aims to "enrich and expand our experience of everyday life" ([21]: 46) by "generat[ing] dilemmas or confusions among users in such a way that users are encouraged to expand their interpretative horizons or rethink cultural norms" ([4]: 289). By so doing, critical design directs attention to issues of public concern. In the context of civic engagement, critical design introduces dilemmas and confusions into the experience of civic issues with the aim to surface multiple, alternative values and spur debate. By problematizing values that are 'hard-wired' into infrastructures of civic engagement, critical design can counter the stasis, complacency, and inertia that can result from the at-hand experience of infrastructure.

\section{Critical Design for the Everyday}

Dilemmas and confusions can also be designed into artifacts of everyday use-furniture or government ID cards, for example $[15,21]$. Hassenzahl et al. advocate for designing everyday artifacts following an 'aesthetics of friction' as opposed to an aesthetics of convenience and efficiency [29, 30, 44]. Based on the psychology of motivation, they recommend designing artifacts that will lead to momentary transformation, subsequent reflection and meaning making, and, taken together, longer-term behavior change [30]. In contrast to many strategies of persuasive design, the emphasis here centers on building from small, mundane, everyday moments of transformation:

The primary objective is, thus, not necessarily maximizing change (e.g., reducing energy consumption) per se, but supporting people with realizing the goals they find worthwhile to pursue, but hard to implement." ([44]: 2) 
These momentary transformations are provoked by a class of technology that they term 'pleasurable troublemakers' [30]. These troublemakers create small but pleasurable obstacles to targeted moments of everyday life, i.e., they create friction. Rather than designing to help or to make everyday life easier, Hassenzahl et al.'s designs engineer pause and provoke reflection, using friction to emphasize the active role individuals should have in constructing meaning of their experiences $[30,44]$.

There is genealogical resonance between theories of the everyday and theories of critical design. Lefebvre's Critique of Everyday Life [49] was a foundational influence on the Situationists, whose art tactics have been taken up by designers and critical theorists in HCI [46]. Lefebvre's critique of the dilution of citizens' everyday agency in politics and civic engagement, which we take up here, parallels his criticism of the passive role of individuals imposed on them by a consumer society. Whereas the Situationists created spectacles to raise awareness and intervene in the consumerist status quo, we advocate for creating friction to raise awareness and intervene in the depoliticized status quo.

\section{From Critical Design to Contestational Design}

Contestational design examines how design can provoke and engage 'the political'- the conflictual values constitutive of human relations $[17,31]$. It aims to challenge beliefs, values, and assumptions by revealing power relationships, reconfiguring what and who is left out, and articulating collective values and counter-values [17]. Contestational design takes a more explicit confrontational approach than critical design does, reflecting an activist stance: "it is an openly partisan activity that advances a particular set of interests, often at the expense of another" ([31]: 11). Based on the political theory of Chantal Mouffe [56], contestational design sees dissensus and confrontation as inherent yet productive aspects of democracy, drawing attention to the plurality of viewpoints that fundamentally can never be fully resolved. Rather than working to resolve differences, contestational design embraces pluralism and seeks ways to engage critically with contentious issues of public concern.

\section{DIMENSIONS FOR THE INFRASTRUCTURING OF CIVIC ENGAGEMENT}

Synthesizing the literature about contestational design and the everyday, we introduce two cross-cutting dimensions that, together, provide a framework for understanding the infrastructuring of civic engagement. Our analysis foregrounds a design space of untapped potential for HCI researchers to provoke civic engagement through contestational design in everyday life.

\section{Everydayness}

Theories of the everyday foreground two perspectives on how politics and civic engagement can be experienced-as confined to 'privileged moments' or as experienced through 'product-residue.' These two perspectives form the first axis of our design space.

\section{Privileged Moments \\ Everyday life includes political life [..]. It enters into permanent contact with the State and the State apparatus thanks to administration and bureaucracy. But on the other hand political life detaches itself from everyday life by concentrating itself in privileged moments (elections, for example), and by fostering specialized activities. ([49]: 114, vol. 1)}

According to Lefebvre, the depoliticization of everyday life confines civic engagement to privileged moments. Foremost, privileged moments are privileged through their status as special activities that occur only infrequently. Yet, privileged moments are also privileged through invitation by institutions of power. When citizens are mere users, "the state is of interest almost exclusively to professionals, specialists in "political science"' ([49]: 754, vol. 3). That is, Lefebvre argues, the state extends the privilege to participate to citizens only when needed. Such privileged moments may be activities during which structures of power designed by experts are merely refined with input and feedback provided by users.

Privileged moments can further be understood reflexively by returning to de Certeau's 'strategies' ([13]: 35ff.). For de Certeau, those with power-i.e., with proprietorship over a space and able to delineate a space of their own distinct from others - are the ones who employ 'strategies' (e.g., laws and regulations, urban design). Strategies of the state, then, define the frame within which citizens can go about their lives. Citizens do not themselves have power over these structures; in order for citizens to influence the frame itself, i.e., the structures of power, the state has to extend opportunities of influence to citizens and it does so only as deemed appropriate-i.e., in privileged moments. Consequently, civic engagement and the political are often relegated to the periphery of everyday life and to specialists who define strategies and identify and construct privileged moments.

\section{Product-Residue}

An understanding of the everyday as product-residue, in contrast, emphasizes the ways in which political life is everyday life ([49]: 114, vol. 1). For Lefebvre, an everyday political life is much more than privileged moments; it is both the product of meaning constructed across specialized and fragmented civic activities (including privileged moments) and the residue of civic life lived between these activities.

An understanding of Lefebvre's product-residue can be expanded through theoretical resonances with de Certeau's 'tactics'. Tactics embody the product-residue. De Certeau characterizes tactics as the practices by which people appropriate the structures they are confronted with, i.e., structures framed through 'strategies' ([13]: 35ff.). By 
putting these structures to use, people invariably produce understandings, interpretations, and opportunities - spaces become neighborhoods, from entertainment people derive values, and grammar and vocabulary are put to use in language [13]. People, then, are not mere consumers of structures of power (of politics). Within and through the ordinary and everyday, people are producers of their own civic lives, engaging with these political structures and thereby actively appropriating them.

De Certeau's tactics embody the product and the residue because they concern conscious and unconscious practices, the activities and their results, the given structures and their derived meanings. In being tactical, people actively engage with, adapt, and appropriate the physical, social, cultural, and political structures in the ordinary and everyday. This appropriation and enactment is fundamentally politicalmoving people form passive consumers to active producers of issues of public concern.

\section{Paradigms of Political Participation}

Scholars in contestational design have pointed toward alternative understandings of civic engagement and the role that technology and design might play in countering the political status quo. Drawing from the political theory of Mouffe [56], they argue for an understanding of civic engagement based on two contrasting theories of and approaches to democracy and participation-what might best be described as a consensual and a contestational view $[2,17,31]$.

\section{Consensus and Convenience}

The consensus and convenience paradigm of political participation emphasizes rationality and consensus as the basis for democratic decision-making and action (e.g., [26, 60, 61]; see [55]). It subscribes to the idea that rational compromise and consensus can be arrived through the deliberation of diverging arguments and viewpoints. Efforts to foster civic engagement following this paradigm typically focus on involving citizens in an efficient and inclusive manner.

As DiSalvo [17] argues, a typical trope of e-democracy initiatives within this paradigm is to improve mechanisms of governance generally and to increase participation of the citizenry through convenience and accessibility. In order to better support the administrative operations of government, initiatives within this trope often translate traditional democratic activities into online tools for participation (e.g., e-deliberation, e-voting, etc.; see [2]). The main concerns of such initiatives center around issues of efficiency, accountability, and equitable access to information and means of ordered expression and action such as petitions, balloting, or voting. They seek to retrofit or replace existing civic activities in order to realize established political ideals and maintain the status quo (see [2]).

\section{Contestation and Critique}

A contrasting perspective on civic participation understands democracy as a condition of forever-ongoing contestation and 'dissensus' $[17,56]$. Political theorist Chantal Mouffe has called this 'agonistic pluralism' [56]: a fundamental multiplicity of voices inherent in social relations that are forever contentious and will never be resolved through mere rationality. Agonistic pluralism is a perspective that seeks to transform antagonism into agonism, moving from conflict among enemies to constructive controversies among 'adversaries' forever in disagreement. Agonistic pluralism emphasizes the non-rational and more affective aspects of political relations. It sees contestation and dissensus as integral, productive, and meaningful aspects of democratic society. As DiSalvo [17] points out:

From an agonistic perspective, democracy is a situation in which the facts, beliefs, and practices of a society are forever examined and challenged. For democracy to flourish, spaces of confrontation must exist, and contestation must occur. ([17]: 5)

Designers have drawn from Mouffe's theoretical position in multiple ways: directly in the form of contestational or adversarial design [17, 31] and indirectly in designing for activist technologies and technologies for protest $[2,33,35$, 37]. In this view, reflection and critical thinking are at the core of civic processes and activities, and provocation and contestation are seen as means to attain these values.

\section{FOUR APPROACHES TO DESIGNING FOR CIVIC ENGAGEMENT}

The two cross-cutting dimensions described above provide the theoretical framework for understanding the infrastructuring of civic engagement. Through our analysis of socio-technical research in the domain of civic engagement, we characterize each of the four quadrants in that design space. These four approaches-deliberation, situated participation, disruption, and friction-have been taken up, albeit unevenly, by designers or researchers to foster civic engagement (Figure 1).

\section{Deliberation}

E-government and e-democracy research has embraced opportunities offered by emerging ICTs and broader-based internet access to translate offline activities of civic engagement into computer-mediated online counterparts [63]. Novel platforms that support the deliberation of civic issues such as urban planning or public policy are common within these bodies of research [7, 23]. Here, the focus of design is often on fostering discourse among stakeholders with differing viewpoints in order to arrive at some form of actionable consensus. Other prototypical systems include platforms for collective decision making-often a more formal conclusion to deliberative processes either affirming, rejecting, or choosing among various alternatives - in the form of e-voting [22, 62]. 


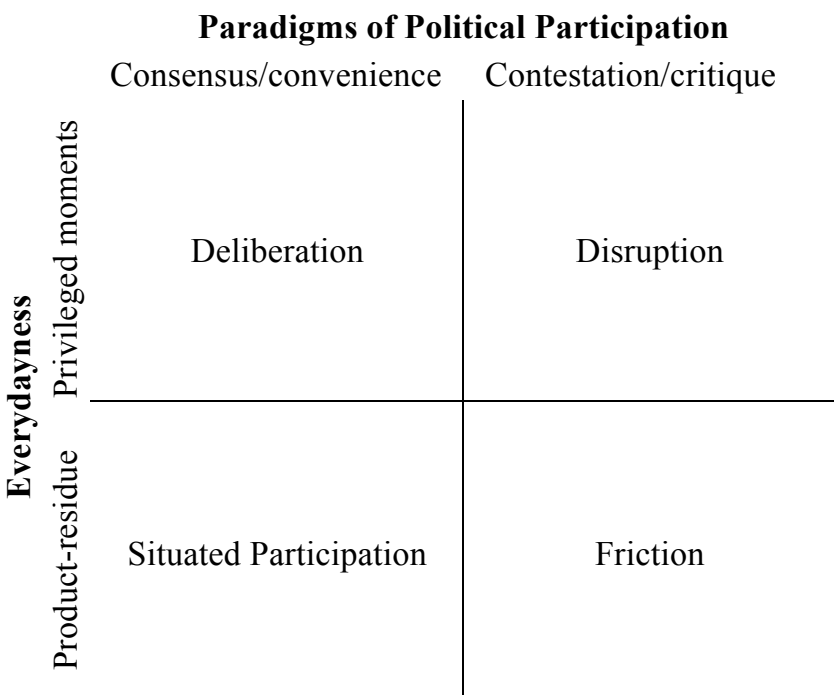

Figure 1. Approaches to designing for civic engagement.

This strand of research often reflects an understanding of civic engagement that is extended as an explicit invitation for participation from the state to the citizen, invitations that are proffered only periodically, either at major electoral junctures or for significant public projects. We see less research supporting discourse about citizen-originated issues in this quadrant; those discourses are more commonly initiated, instead, through everyday, productresidue infrastructures of engagement.

Research supporting deliberation has been foundational in moving civic engagement online and much of this research has shown promise in finding ways to increase the participation in and quality of civic discourse, enabling more broad-based, actionable forms of consensus. But this strand of research still relegates citizenship to the periphery of everyday life taking place only in privileged moments.

\section{Situated Participation}

The strand of research fostering civic engagement through situated participation has capitalized on opportunities to embed civic engagement in everyday life through novel networked, mobile, and ubiquitous technologies. These systems resonate with Weiser's vision of ubiquitous computing by emphasizing technology that dissolves into the everyday [77], interleaving civic engagement between and across temporal, social, and spatial contexts of activity. Through this embedding, research supporting situated participation has aimed at aggregating local knowledge and understanding local needs of citizens that can be valuable resources in planning processes but are often difficult to obtain.

Increasingly, research in e-democracy and e-government has shifted from facilitating state-initiated invitations to deliberation to leveraging online platforms for anytime, ongoing civic interactions $[6,11,38,73]$. This research has transformed previously discrete engagement mechanisms into infrastructures supporting ongoing dialogue (temporal embedding) about a variety of civic issues, from neighborhood living to public service provision. This continuous involvement stands in contrast to civic participation only in 'privileged moments'.

With the rise in popularity of social media, other research in this vein integrates civic engagement and particularly advocacy into people's online and offline social networks (social embedding) [16, 28, 53, 65]. Such research seeks to build, extend, or connect communities of interest around shared causes. Its focus ranges from generating awareness of civic issues [28], to enabling debate and discussion [53, $65]$, to motivating and rallying for action $[16,53]$.

A third strand of embedded approaches to fostering civic engagement is to spatially align engagement opportunities with people's whereabouts in the city (spatial embedding) - particularly in domains where spatiality plays a central role such as urban planning [40, 64]. Spatially situated engagement seeks to make relevant and meaningful to people the issues and topics of discussion that are in their close proximity as they move about their day [40]. Spatially situated technologies for civic engagement range from being stationary (installed at places of interest; e.g., [36, 64, $69,75]$ ), to mobile (typically location-based and often with rich media capturing capabilities; e.g., [5, 27, 41, 50]), to ubiquitous (more deeply embedded into the fabric of the city in the form of sensors, smaller pervasive displays, ubiquitous input/output modalities, etc.; e.g., [43, 72]).

While researchers design for situated participation are concerned with unobtrusively integrating civic engagement into people's daily lives, they, at the same time, are nudging and reminding people of participation opportunities that may be relevant to their interests through strategies such as personalization or notifications $[5,40]$.

Some of the research focused on embedding civic engagement into everyday life manifests a view of civic engagement as a form of one-way issue or bug reporting on public services and infrastructures [24, 42]. Citizens are encouraged to report the small, mundane nuisances that get in the way of leading a 'productive' everyday life. This research often mines local knowledge, relying on citizensas 'users' of a city - to maintain, repair, and improve the efficient operation of public services and infrastructures. A related, but larger-scale, strand of research leverages large crowds of people in a more automated fashion (e.g., as 'sensors') to contribute data about issues of civic relevance such as problems with physical infrastructure or shared environmental concerns [54, 57]. In contrast to these two strands, other approaches seek to foster active dialogue, community, and more permanent relationships among citizens and with the state $[5,41,50]$.

In sum, research in this quadrant focuses on rationale dialogue and harmonious relationships-both among communities and with the state. And it does so while 
embodying the product-residue. This research emphasizes the in-between aspects of everyday life. Designs target people's commuting, going about, and everyday curiosity, seeking to only minimally disrupt by providing options for quick feedback and the capturing of small memory cues for later. Research here also targets the holistic product of the fragmented activities of everyday life by fostering productive dialogue, community building, and sustained relationships among citizens and with the state.

\section{Disruption}

Research fostering disruption provides mechanisms for citizens to reveal, address, reflect on, and/or call into question the status quo of values, assumptions, and beliefs held by a community. It does so by focusing on 'privileged moments' of dissensus, protest, and civic disobedience. According to Castells [12], moments of collective civic disobedience arise when people overcome anxiety through moments of outrage and anger, when others experience similar moments of injustice that they also share, and when enthusiasm emerges and hope rises through identification and togetherness ([12]: 13-15).

Researchers have studied the use of technologies during demonstrations, occupations of public squares, and protest actions at sites of interest to the local community $[2,35$, 71]. Research in this vein frequently focuses on communication and coordination practices. Such practices concern, e.g., the sharing, mobilization, and dissemination of causes and protest actions on social media [2, 71], or the coordination work required during decentralized forms of protest, e.g., via FM radio, mobile phones, and text messaging [33, 35].

Activist moments of civic engagement typically entail responding opportunistically to dynamic political, legal, and technical environments [33]. Hence, activist technologies often support immediate, short-lived campaigns and events that result in a number of individual protest actions [2, 33]. However, research has also begun to focus beyond the individual system to larger infrastructural goals. Hirsch [32] has found that while activists appropriate technologies for individual projects in a quick-and-dirty fashion, they often aim to serve multiple communities or protest actions on the basis of a single development effort. In addition, activists adopt and implement these technologies in ways that create infrastructural redundancies and resilience [33]. Asad and Le Dantec [2] have similarly argued for open, flexible, and underdetermined design of platforms for activists that support a range of practices over time.

In addition to supporting individual or repeated activities of protest and activism, research has also studied situations of ongoing crisis, military occupation, and open conflict [71, 78, 79]. Wulf et al. [78], e.g., found that social media came to be used as a way to organize regular demonstrations, to communicate and interact with local and global networks of supporters, and to offer information to the broader public.
Privileged moments of civic disobedience are also reflected in Participatory Design research $[15,18,51]$. Inspired by Agre's [1] 'critical technical practice' and Ratto's [59] 'critical making' — which emphasize linking socio-political critique with technical projects through hands-on construction and situated reflection-this research invites and encourages citizens to co-construct alternative values during participatory design workshops. It concerns itself with exploring alternative values related to environmental sustainability, local neighborhood communities, or privacy in governmental identification schemes [15, 18].

Whereas this contestational strand of research in civic HCI began by supporting individual protest activities and moments of civic disobedience, it has increasingly acknowledged recurring practices, the re-appropriation of technologies, and the need for infrastructural support for continued and ongoing activism.

\section{Friction}

Research employing friction as a design strategy embodies both an engagement with the product-residue of the everyday and with a philosophy that politics is fundamentally contestational. Here, civic engagement is emancipated from privileged moments-those fragmented or, even, recurring fragmented activities - and interleaved into the product and residue of everyday life. This transition shifts the unit of analysis from the activity to the smallerscale gaps and spaces in between activities and the largerscale implications of those activities. The contestational design approach provokes citizens to reflect and question the status quo with respect to the conditions of the productresidue of civic life. We find a dearth of research that embodies this approach to designing for civic engagement, and so we engage with the only two examples we can find in more detail.

Clement et al. [15] create friction through the adversarial redesign of identity infrastructures that receive everyday use. Their speculative overlays for government-issued ID cards allow citizens to temporarily black out information unnecessarily exposed by default in numerous situations (e.g., buying alcohol requires sharing your photo and date of birth but not your name or address). The overlays present small obstacles in a larger infrastructure that citizens are confronted with on an everyday basis, provoking them to question the means of government identification and reflect on privacy more generally.

We find another example of friction in research that has explored alternative and oppositional media [32, 34, 51]. Activists have long sought to facilitate the exchange of alternative voices-particularly, but not exclusively so within state-controlled (i.e., monitored and/or censored) media landscapes. Research in alternative media explores ways to bypass government control and allow the dissemination of potentially dissenting information via alternative news channels. By building on top of other 
stable and pervasive infrastructures (e.g., the web [34] or mobile phone networks [32]), at times in parasitic relationships, activists subvert these infrastructures and put them to new and alternative use. Here, alternative media use escapes privileged moments by undercutting the power relationship that allows the state to define what constitutes privilege.

Both examples of design for friction foreground the significant role of infrastructuring when the everyday is emphasized. Yet, as infrastructures are slow to change and susceptible to inertia, particular design strategies have been employed to work through and around existing infrastructures, applying contestation, provocation, and critique to question the status quo and counter inertia. Given the dearth of examples of friction applied in designs for civic engagement and the promise suggested by these initial examples, we turn next to expand on 'friction' as a strategy for bringing everyday provocation to the infrastructuring of civic engagement.

\section{CREATING FRICTION: INFRASTRUTURING CIVIC ENGAGEMENT IN EVERYDAY LIFE}

Hassenzahl et al. have identified four principles for designing persuasive artifacts within an 'aesthetics of friction', which we take as a starting point for exploring how to create friction through the infrastructuring of civic engagement [29, 30, 44]:

\section{Designs for friction take a position or a stance. They are not neutral.}

No technologies are value-neutral. And, certainly, any designers who intend to foster civic engagement have taken something of an activist stance in their research, even if implicitly. But designs for friction take an explicit stance toward their users. In the case of infrastructuring civic engagement, designs for friction take the stance that users should be citizens and that the most foundational and requisite work of infrastructuring civic engagement has to come from building the social infrastructure of citizenry-provoking individuals to identify themselves not as users but as citizens in the most active sense possible.

2. Designs for friction want to cause trouble. They do not want to help you; rather, they place little obstacles in your way.

Designs for friction do not merely blend activities of civic engagement seamlessly into everyday life, enabling participation 'anytime, anywhere'. They do not make civic engagement more efficient or convenient for citizens. Rather, in the vein of contestational design, creating friction in infrastructures of civic engagement means making citizens pause and reflect-reflect on alternative civic values, reflect on the status quo of civic doing and acting, reflect on the viewpoints of others, and reflect on one's agency as a citizen... not user. The little obstacles of friction carve out space for reflection in the residue between activities and in doing so counter the stasis and complacency caused by typical infrastructures.

\section{Designs for friction are naïve and inferior. They are not intelligent.}

Designs for friction do not take agency away from the citizenry. They do not make use of 'intelligent' algorithms to anticipate and represent individuals in civic participation. Rather than staking a claim to values and ideals identified a priori by designers, they provoke individuals to articulate and stake a claim to their own values and ideals. Within infrastructures of civic engagement, designing for friction is not primarily about exerting or extending more power per se, but about making room for and creating opportunities for citizens to take power and ownership over issues of public concern.

4.Designs for friction are not absolute. They acknowledge that although change is desirable, it still lies in the hands of individuals with agency.

Designs for friction, because they acknowledge the agency of citizens, cannot impose change. Citizens ultimately retain agency over if and when change happens and if or when reflection about civic life happens. Designs for friction provide opportunities, not mandates. There is always an alternative to acknowledging, responding to, or using infrastructures of civic engagement. Frictional infrastructures do not stop citizens from carrying on as intended; they do not break down completely in the face of inaction or disinterest. Rather, they serve to make citizens pause, to be disruptive without bringing things to a halt. Friction happens in a flicker of a moment in the product-residue of everyday life.

\section{Design Strategies}

Previous research that we see as embodying infrastructural friction, both within and outside the domain of civic engagement, has employed a variety of different strategies for doing so. Synthesizing this existing research, we identify and characterize an initial suite of design strategies for infrastructuring civic engagement by creating friction.

\section{- Infrastructuring through intervention}

When citizens do not maintain control over existing infrastructures, strategies of subversive intervention have been used to create what we would identify as friction. For example, research has sought to intervene in established, large-scale infrastructures by manipulating the representations of infrastructure that citizens hold in their hands (e.g., overlays for government ID cards [15]). This case of everyday appropriation of 'imposed' infrastructure is reminiscent of de Certeau's 'tactics', and emphasizes infrastructure's relational and potentially evolving character at the interlay between standardization and local practices. Research has also taken to "graft a new infrastructure onto an existing one" ([37]: 616) in order to reveal previously invisible relationships between various actors within the existing infrastructure, 
empowering a central but previously disenfranchised stakeholder population in their everyday (work) lives. Strategies of intervention, then, shift the arrangements of power and, in doing so, nudge the infrastructures themselves toward change.

\section{- Infrastructuring by creating alternatives}

Other research has created what we would identify as friction by building alternative infrastructures in parallel to existing ones to facilitate a pluralism of voices (e.g., alternative media channels $[32,51]$ or parallel communication infrastructures [33]). Such alternative infrastructures typically 'piggy-back' on existing, stable, and pervasive infrastructures [33], introducing additional layers and ways around established forms of power embedded in infrastructure. This design strategy, then, suggests a mechanism for undercutting and questioning power relationships that define what constitutes privilege and, thus, the structures underlying privileged moments that constrain civic engagement.

\section{- Infrastructuring by making gaps visible}

To foreground and leave open (rather than to close and remove) gaps or seams within and between infrastructures is another strategy that we identify from previous research as embodying friction (e.g., [52]). 'Seamful design' does so by "selectively and carefully revealing differences and limitations of systems" ([14]: 251) and the underlying infrastructural mechanisms between them. If appropriated for friction, moments of infrastructural breakdown can become moments of awareness, reflection, and questioning about the activities that infrastructures enable and the values inscribed in them, moving beyond the mere feedback cycles of 'users' of public services. For infrastructures of civic engagement, then, seams and gaps provide both the space in which to design for friction as well as the substance of everyday residue on which citizens may be provoked to reflect.

\section{- Infrastructuring by using trace data for critique}

A final strategy amenable for creating friction is one of employing trace data of infrastructural use in order to critique those infrastructures, or even to reveal them in the first place. For example, researchers have visualized the traces individuals leave behind when surfing the web in order to uncover and ultimately critique large-scale, commercial data mining practices [39]. Working with trace data hints at such a strategy's power to emphasize the relationship between the residue of activities and their product. Working with trace data related to civic engagement could foreground issues of data ownership and opportunities for challenging power dynamics [76].

The four design strategies described above primarily act as subversive forces, working to enact change from outside the centers of power over these infrastructures. However, frictional design does not necessarily have to be applied exclusively from the outside. Rather, we posit friction to be a mechanism that is also applicable to the design of infrastructures of civic engagement in the hands of those in power, and in their best interest, in order to counter issues of stasis and complacency and to reach toward the ideal of the 'more active citizen'.

\section{FUTURE WORK}

We see three open questions as being productive areas for future research.

Facilitating a shift from user to citizen is a cultural process through which peripheral participants are scaffolded or provoked toward more expert participation [45]. While Lave and Wenger caution against understanding situated learning as a movement from the periphery to the center, we do imagine that the movement from user to citizen, from periphery to expert, will interact in some significant ways with where one stands with respect to the institutions of influence over infrastructure. Bowker and Star [9] warn that individuals farther removed from these centers of power will more strongly experience torque from the values embedded into the infrastructure. Studies of infrastructures of civic engagement, then, will need to pay particular attention to understanding how legitimate peripheral participation can be supported while avoiding the disenfranchisement that comes with being too far at the periphery. Frictional infrastructures are likely to be a good first step as the little obstacles they place in the everyday may more readily suggest possibilities of opting out than other infrastructures (see also [52]), but this is a question that necessitates more empirical work.

In this paper, we advocate for frictional design contesting the status quo of citizen-state relationships. Yet, Lefebvre -and the Situationists he inspired - as well as de Certeau also deeply engage with questions of 'passive' consumers as political actors $[13,49]$. Research has already sought to inject and intervene in the prevailing metaphor of markets $[37,39]$. Infrastructuring corporate arrangements of power, then, is a direction for which future research may fruitfully mobilize frictional design strategies.

Lastly, we assume quite pragmatically that the research community will need to explore a balance between the benefits and annoyances of friction. Friction is likely not to scale, for example, to every situation of civic engagement in which we expect individuals to find themselves. An empirical question for future research, then, is for whom, in what contexts, and over what periods of time is friction useful - and for whom, in what contexts, and after what periods of time does it stop being useful-for addressing the dual challenges of infrastructuring civic engagement. There are also related questions about how one's identity and participation as a citizen evolves, as we assume that designs for friction will need to be nimble enough to engage citizens through the ebb and flow of engagement. From an infrastructuring perspective, this is ultimately a question about sustainability. 


\section{CONCLUSION}

Bowker [8] has argued for research to undertake 'infrastructural inversion'-subverting the traditional figure/ground relationship that perpetuates the analytic invisibility of infrastructures. In this research, we reposition infrastructural inversion as an approach to design rather than as ethnographic practice. The use of friction when infrastructuring civic engagement is a designerly enactment of infrastructural inversion. Friction is positioned to foreground infrastructures through everyday obstacles that counter the potential of stasis and complacency.

In this paper, we have introduced theories of the everyday to the emerging bodies of research on contestational design and infrastructures of civic engagement. Our research contributes a design space distilling and describing four distinct approaches to designing for civic engagement, including deliberation, disruption, situated participation, and friction. We argue that there is untapped potential for designing for friction-for leveraging critique and contestation as means of re-unifying politics and the everyday.

\section{ACKNOWLEDGMENTS}

We thank Susann Wagenknecht for feedback on early drafts of the paper. This material is based upon work supported by the National Science Foundation under Grant Number 1360035. Any opinions, findings, and conclusions or recommendations expressed in this material are those of the author(s) and do not necessarily reflect the views of the National Science Foundation.

\section{REFERENCES}

1. Agre, P. (1997). Toward a critical technical practice: Lessons learned in trying to reform AI. In G. Bowker, S.L. Star, W. Turner, \& L. Gasser (Eds.), Social Science, Technical Systems, and Cooperative Work: Beyond the Great Divide, Hillsdale: Erlbaum, 131-158.

2. Asad, M. \& Le Dantec, C. (2015). Illegitimate civic participation: supporting community activists on the ground. In Proc. CSCW 2015. ACM Press, 1694-1703.

3. Bardzell, J. \& Bardzell, S. (2013). What is "critical" about critical design? In Proc. CHI 2013. ACM Press, 3297-3306.

4. Bardzell, S., Bardzell, J., Forlizzi, J., Zimmerman, J., \& Antanitis, J. (2012). Critical design and critical theory: the challenge of designing for provocation. In Proc. DIS 2012. ACM Press, 288-297.

5. Bohøj, M., Borchorst, N.G., Bødker, S., Korn, M., \& Zander, P.-O. (2011). Public deliberation in municipal planning: supporting action and reflection with mobile technology. In Proc. C\&T 2011. ACM Press, 88-97.

6. Borchorst, N.G., Bødker, S., \& Zander, P.-O. (2009). The boundaries of participatory citizenship. In Proc. ECSCW 2009. Springer, 1-20.

7. Borning, A., Friedman, B., Davis, J., \& Lin, P. (2005). Informing public deliberation: value sensitive design of indicators for a large-scale urban simulation. In Proc. ECSCW 2005. Springer, 449-468.

8. Bowker, G. (1994). Information mythology: The world of/as information. In L. Bud-Frierman (Ed.),

Information Acumen: The Understanding and Use of Knowledge in Modern Business (pp. 231-247). London: Routledge.

9. Bowker, G.C. \& Star, S.L. (1999). Sorting Things Out. Cambridge: MIT Press.

10. Bødker, S. (2006). When second wave HCI meets third wave challenges. In Proc. NordiCHI 2006. ACM Press, $1-8$.

11. Carroll, J.M. \& Rosson, M.B. (1996). Developing the Blacksburg electronic village. Commun. ACM 39(12), 69-74.

12. Castells, M. (2012). Networks of Outrage and Hope: Social Movements in the Internet Age. Cambridge: Polity Press.

13. de Certeau, M. (1984). The Practice of Everyday Life. Berkeley: University of California Press.

14. Chalmers, M. \& Galani, A. (2004). Seamful interweaving: heterogeneity in the theory and design of interactive systems. In Proc. DIS 2004. ACM Press, 243-252.

15. Clement, A., McPhail, B., Smith, K.L., \& Ferenbok, J. (2012). Probing, mocking and prototyping: participatory approaches to identity infrastructuring. In Proc. PDC 2012, ACM Press, 21-30.

16. Crivellaro, C., Comber, R., Bowers, J., Wright, P.C., \& Olivier, P. (2014). A pool of dreams: Facebook, politics and the emergence of a social movement. In Proc. CHI 2014. ACM Press, 3573-3582.

17. DiSalvo, C. (2012). Adversarial Design. Cambridge: MIT Press.

18. DiSalvo, C., Nourbakhsh, I., Holstius, D., Akin, A., \& Louw, M. (2008). The Neighborhood Networks project: a case study of critical engagement and creative expression through participatory design. In Proc. PDC 2008. ACM Press, 41-50.

19. Dourish, P. \& Bell G. (2007). The infrastructure of experience and the experience of infrastructure: meaning and structure in everyday encounters with space. Environment and Planning B: Planning and Design 34(3), 414-430.

20. Dourish, P. \& Bell, G. (2011). Divining a Digital Future: Mess and Mythology in Ubiquitous Computing. Cambridge: MIT Press.

21. Dunne, A. \& Raby, F. (2001). Design Noir: The Secret Life of Electronic Objects. Basel: Birkhäuser.

22. Everett, S.P., Greene, K.K., Byrne, M.D., Wallach, D.S., Derr, K., Sandler, D., \& Torous, T. (2008). Electronic voting machines versus traditional methods: improved 
preference, similar performance. In Proc. CHI 2008. ACM Press, 883-892.

23. Farina, C., Epstein, D., Heidt, J., \& Newhart, M. (2014). Designing an online civic engagement platform: Balancing 'more' vs. 'better' participation in complex public policymaking. International Journal of E-Politics 5(1), 16-40.

24. Foth, M., Schroeter, R., \& Anastasiu, I. (2011). Fixing the city one photo at a time: mobile logging of maintenance requests. In Proc. OzCHI 2011. ACM Press, 126-129.

25. Galloway, A. (2004). Intimations of everyday life: Ubiquitous computing and the city. Cultural Studies 18(2/3), 384-408.

26. Habermas, J. (1996). Between Facts and Norms. Contributions to a Discourse Theory of Law and Democracy. Cambridge: MIT Press.

27. Halttunen, V., Juustila, A., \& Nuojua, J. (2010). Technologies to support communication between citizens and designers in participatory urban planning process. In S. Wallin, L. Horelli, \& J. Saad-Sulonen (Eds.), Digital Tools in Participatory Planning (pp. 79-91). Centre for Urban and Regional Studies, Aalto University.

28. Han, K., Shih, P.C., \& Carroll, J.M. (2014). Local News Chatter: augmenting community news by aggregating hyperlocal microblog content in a tag cloud. International Journal of Human-Computer Interaction 30(12), 1003-1014.

29. Hassenzahl, M. (2011). Towards an Aesthetic of Friction. TEDxHogeschoolUtrecht. http://youtu.be/ ehWdLEXSoh8 (Retrieved: Dec. 10, 2014).

30. Hassenzahl, M. \& Laschke, M. (2015). Pleasurable troublemakers. In S.P. Walz \& S. Deterding (Eds.), The Gameful World: Approaches, Issues, Applications (ch. 6, pp. 167-195). Cambridge: MIT Press.

31. Hirsch, T. (2008). Contestational Design: Innovation for Political Activism. Unpublished PhD Dissertation, Massachusetts Institute of Technology.

32. Hirsch, T. (2009). Communities real and imagined: designing a communication system for Zimbabwean activists. In Proc. C\&T 2009. ACM Press, 71-76.

33. Hirsch, T. (2009). Learning from activists: lessons for designers. interactions 16(3), 31-33.

34. Hirsch, T. (2011). More than friends: social and mobile media for activist organizations. In M. Foth, L. Forlano, C. Satchell, \& M. Gibbs (Eds.), From Social Butterfly to Engaged Citizen (pp. 135-150). Cambridge: MIT Press.

35. Hirsch, T. \& Henry, J. (2005). TXTmob: Text messaging for protest swarms. In Ext. Abstracts $\mathrm{CHI}$ 2005. ACM Press, 1455-1458.

36. Hosio, S., Kostakos, V., Kukka, H., Jurmu, M., Riekki, J., \& Ojala, T. (2012). From school food to skate parks in a few clicks: using public displays to bootstrap civic engagement of the young. In Proc. Pervasive 2012. Springer, 425-442.

37. Irani, L.C. \& Silberman, M.S. (2013). Turkopticon: Interrupting worker invisibility in Amazon Mechanical Turk. In Proc. CHI 2013. ACM Press, 611-620.

38. Kavanaugh, A., Carroll, J.M., Rosson, M.B., Zin, T.T., $\&$ Reese, D.D. (2005). Community networks: where offline communities meet online. Journal of ComputerMediated Communication 10(4).

39. Khovanskaya, V., Baumer, E.P.S., Cosley, D., Voida, S., \& Gay, G. (2013). "Everybody knows what you're doing": a critical design approach to personal informatics. In Proc. CHI 2013. ACM Press, 3403-3412.

40. Korn, M. (2013). Situating Engagement: Ubiquitous Infrastructures for In-Situ Civic Engagement. Unpublished PhD Dissertation, Aarhus University.

41. Korn, M. \& Back, J. (2012). Talking it further: from feelings and memories to civic discussions in and about places. In Proc. NordiCHI 2012. ACM Press, 189-198.

42. Korsgaard, H. \& Brynskov, M. (2014). City bug report: urban prototyping as participatory process and practice. In Proc. MAB 2014. ACM Press, 21-29.

43. Kuznetsov, S. \& Paulos, E. (2010). Participatory sensing in public spaces: activating urban surfaces with sensor probes. In Proc. DIS 2010. ACM Press, 21-30.

44. Laschke, M., Hassenzahl, M., \& Diefenbach, S. (2011). Things with attitude: Transformational products. In Proc. Create11: The Interaction Design Symposium, London, UK, 23rd June 2011, http://www.createconference.org/storage/create 1 1papersposters/Things $\% 2$ 0with\%20attitude.pdf (Retrieved: Dec. 10, 2014).

45. Lave, J. \& Wenger, E. (1991). Situated Learning: Legitimate Peripheral Participation. Cambridge: Cambridge University Press.

46. Leahu, L., Thom-Santelli, J., Pederson, C., \& Sengers, P. (2008). Taming the Situationist beast. In Proc. DIS 2008. ACM Press, 203-211.

47. Le Dantec, C.A. \& DiSalvo, C. (2013). Infrastructuring and the formation of publics in participatory design. Social Studies of Science 43(2), 241-264.

48. Lee, C.P., Dourish, P. \& Mark, G. (2006). The human infrastructure of cyberinfrastructure. In Proc. CSCW 2006. ACM Press, 483-492.

49. Lefebvre, H. (2014). Critique of Everyday Life. London: Verso.

50. Lehner, U., Baldauf, M., Eranti, V., Reitberger, W., \& Fröhlich, P. (2014). Civic engagement meets pervasive gaming: towards long-term mobile participation. In Ext. Abstracts CHI 2014. ACM Press, 1483-1488.

51.Lievrouw, L.A. (2006). Oppositional and activist new media: remediation, reconfiguration, participation. In Proc. PDC 2006. ACM Press, 115-124. 
52. Mainwaring, S.D., Cheng, M.F., \& Anderson, K. (2004). Infrastructures and their discontents: Implications for Ubicomp. In Proc. Ubicomp 2004. Springer, 418-432.

53. Mascaro, C.M. \& Goggins, S.P. (2011). Brewing up citizen engagement: the Coffee Party on Facebook. In Proc. C\&T 2011. ACM Press, 11-20.

54. Monroy-Hernández, A., Farnham, S., Kiciman, E., Counts, S., \& De Choudhury, M. (2013). Smart societies: from citizens as sensors to collective action. interactions 20(4), 16-19.

55. Mouffe, C. (2000). Deliberative Democracy or Agonistic Pluralism. Political Science Series 72. Vienna: Institute for Advanced Studies.

56. Mouffe, C. (2013). Agonistics: Thinking the World Politically. London: Verso.

57. Paulos, E., Honicky, RJ, \& Hooker, B. (2009). Citizen science: Enabling participatory urbanism. In M. Foth (Ed.), Handbook of Research on Urban Informatics (ch. XXVIII, pp. 414-436). Hershey, PA: IGI Global.

58. Pipek, V. \& Wulf, V. (2009). Infrastructuring: Toward an integrated perspective on the design and use of information technology. Journal of the Association of Information Systems 10(5), 447-473.

59. Ratto, M. (2011). Critical making: Conceptual and material studies in technology and social life. The Information Society 27(4), 252-260.

60. Rawls, J. (1971). A Theory of Justice. Cambridge: Harvard University Press.

61. Rawls, J. (1993). Political Liberalism. New York: Columbia University Press.

62. Robertson, S.P. (2005). Voter-centered design: Toward a voter decision support system. ACM Trans. Comput.Hum. Interact. 12(2), 263-292.

63. Robertson, S.P. \& Vatrapu, R.K. (2010). Digital government. Ann. Rev. Info. Sci. Tech. 44(1), 317-364.

64. Schroeter, R., Foth, M., \& Satchell, C. (2012). People, content, location: sweet spotting urban screens for situated engagement. In Proc. DIS 2012. ACM Press, $146-155$.

65. Semaan, B.C., Robertson, S.P., Douglas, S., \& Maruyama, M. (2014). Social media supporting political deliberation across multiple public spheres: towards depolarization. In Proc. CSCW 2014. ACM Press, 1409-1421.

66. Sengers, P., Boehner, K., David, S., \& Kaye, J. (2005). Reflective design. In Proc. Aarhus 2005: Critical Computing. ACM Press, 49-58.

67. Star, S.L. \& Bowker, G.C. (2006). How to infrastructure. In L.A. Lievrouw \& S. Livingstone (Eds.), Handbook of
New Media: Student Edition (pp. 230-245). Thousand Oaks: Sage.

68. Star, S.L. \& Ruhleder, K. (1996). Steps toward an ecology of infrastructure: Design and access for large information. Information Systems Research 7(1), 111134.

69. Taylor, N., Marshall, J., Blum-Ross, A., Mills, J., Rogers, J., Egglestone, P., Frohlich, D.M., Wright, P., \& Olivier, P. (2012). Viewpoint: empowering communities with situated voting devices. In Proc. CHI 2012. ACM Press, 1361-1370.

70. Tsing, A.L. (2005). Friction: An ethnography of global connection. Princeton: Princeton University Press.

71. Tufekci, Z. \& Wilson, C. (2012). Social media and the decision to participate in political protest: Observations from Tahrir Square. Journal of Communication 62(2), 363-379.

72. Vlachokyriakos, V., Comber, R., Ladha, K., Taylor, N., Dunphy, P., McCorry, P., \& Olivier, P. (2014). PosterVote: expanding the action repertoire for local political activism. In Proc. DIS 2014. ACM Press, 795804.

73. Voida, A., Dombrowski, L., Hayes, G.R., \& Mazmanian, M. (2014). Shared values/conflicting logics: working around e-government systems. In Proc. CHI 2014. ACM Press, 3583-3592.

74. Voida, A., Yao, Z., \& Korn, M. (2015). (Infra)structures of volunteering. In Proc. CSCW 2015. ACM Press, 1704-1716.

75. Wagner, I., Basile, M., Ehrenstrasser, L., Maquil, V., Terrin, J.-J., \& Wagner, M. (2009). Supporting community engagement in the city: urban planning in the MR-tent. In Proc. C\&T 2009. ACM Press, 185-194.

76. Weise, S., Hardy, J., Agarwal, P., Coulton, P., Friday, A., \& Chiasson, M. (2012). Democratizing ubiquitous computing: a right for locality. In Proc. UbiComp 2012. ACM Press, 521-530.

77. Weiser, M. (1991). The computer for the 21 st century. Scientific American 265, 94-104.

78. Wulf, V., Aal, K., Kteish, I.A., Atam, M., Schubert, K., Rohde, M., Yerousis, G.P., \& Randall, D. (2013). Fighting against the wall: social media use by political activists in a Palestinian village. In Proc. CHI 2013. ACM Press, 1979-1988.

79. Wulf, V., Misaki, K., Atam, M., Randall, D., \& Rohde, M. (2013). 'On the ground' in Sidi Bouzid: investigating social media use during the Tunisian revolution. In Proc. CSCW 2013. ACM Press, 1409-1418.

80.Zerubavel, E. (1991). The Fine Line: Making Distinctions in Everyday Life. Chicago: University of Chicago Press. 